\title{
Enem: uma análise do efeito das políticas públicas educacionais em Alagoas e a comparação do resultado do ranking com os demais estados do Nordeste
}

\author{
Enem: an analysis of the effect of educational public policies in Alagoas and \\ the comparison of the ranking result with other states of the Northeast \\ Enem: un análisis del efecto de las políticas públicas educativas en Alagoas y \\ la comparación del resultado de la clasificación con los otros \\ estados del Nordeste \\ DANIEL CABRAL DE ALMEIDA \\ VICTOR HUGO LESSA PIERRE \\ CARLOS EUGÊNIO SILVA DA COSTA \\ LUCIANA PEIXOTO SANTA RITA \\ IBSEN MATEUS BITTENCOURT SANTANA PINTO
}

Resumo: $\mathrm{O}$ artigo analisa os resultados de Alagoas no ranking do Exame Nacional do Ensino Médio entre 2013 e 2015, comparando-os com os demais estados do Nordeste. Identificam-se as especificidades que contribuem para a conquista das melhores notas e a aplicação das políticas públicas educacionais em Alagoas. Usou-se a abordagem de pesquisa quali-quantitativa. Identificou-se que as escolas da Bahia e de Pernambuco detêm os melhores resultados do Nordeste e estimou-se que o nível socioeconômico tem grande influência nos resultados das escolas. Registrou-se ainda que o indicador de formação docente parece não ser ponto chave na elevação das notas.

Palavras-chave: Ranking do ENEM; políticas públicas educacionais; Alagoas.

Abstract: The article analyzes the results of Alagoas in the ranking of the National Exam of High School (ENEM) between 2013 and 2015, comparing them with the other states of the Northeast. We identify the specificities that contribute to the achievement of the best grades and the application of educational public policies in Alagoas. The qualitative-quantitative research approach was used. It was identified that the schools of Bahia and Pernambuco have the best results in the Northeast and it was estimated that the socioeconomic level has a great influence on the results of the schools. It was also recorded that the indicator of teacher education does not seem to be a key point in the increase of grades.

Keywords: ENEM ranking; educational public policies; Alagoas.

Resumen: El artículo analiza los resultados de Alagoas en la clasificación del Examen Nacional de la Enseñanza Secundaria entre 2013 y 2015, comparando con los demás estados del Nordeste. Se identifican las especificidades que contribuyen a la conquista de las mejores calificaciones y aplicación de las políticas públicas educativas en Alagoas. Se utilizó el enfoque de investigación cualitativa y cuantitativa. Se identificó que las escuelas en Bahía y Pernambuco tienen los 
mejores resultados en el noreste y se estimó que el nivel socioeconómico tiene una gran influencia en los resultados de las escuelas. Se registró, aún, que el indicador de la formación del profesorado no parece ser el punto clave en la elevación de las notas.

Palabras clave: Clasificación de ENEM; políticas públicas educativas; Alagoas.

\section{INTRODUÇÃO}

A educação, seja nos países desenvolvidos ou em desenvolvimento, tem importância indiscutível por sua capacidade de contribuir no aumento do desenvolvimento social e econômico de um país. Estudos mostram que a promoção de uma educação de qualidade tem reflexos nos aspectos sociais e econômicos, como crescimento da economia local, ampliação do mercado de trabalho, promoção da inclusão social, redução da criminalidade, diminuição das desigualdades sociais, aumento dos níveis salariais e fortalecimento da democracia (MENEZES, 2007).

Barbosa Filho e Pessoa (2010) destacam que a educação tem a capacidade de aumentar a proximidade entre as pessoas, facilitar a comunicação, reduzir a criminalidade, aumentar o nível de consciência política e proporcionar certo controle de natalidade. Dessa forma, propõe-se à redução de diversos problemas sociais. Uma das formas de classificar a qualidade do nível educacional das escolas dos estados da federação e do Distrito Federal, bem como da União e dos municípios que ministram o Ensino Médio, tem sido através da realização da prova do Exame Nacional do Ensino Médio (ENEM), adotado pelo Ministério da Educação (MEC).

Diante desse contexto, identificou-se que o baixo nível educacional se deve também ao baixo desempenho das ações governamentais e políticas públicas educacionais adotadas em determinada região. $\mathrm{O}$ artigo busca identificar as melhores práticas de políticas públicas educacionais que podem ser adotadas a fim de se estabelecer uma evolução educacional positiva, que possa surtir efeito não só no ranking do ENEM, mas também de forma definitiva sobre os aspectos sociais. Além do mais, buscou-se apontar quais variáveis instituídas pelo MEC - por meio do ENEM - mais impactam no desempenho das escolas públicas estaduais de Alagoas e como as políticas públicas educacionais podem ajudá-las a alcançar melhor colocação.

Investigaram-se também as variáveis mais impactantes em Alagoas e sua relação com os resultados dos outros estados nordestinos com base nos dados fornecidos pelo INEP. Por fim, propuseram-se políticas públicas educacionais para a elevação do desempenho estadual no ENEM. 
O estudo justifica-se ante a necessidade de se formularem políticas públicas educacionais eficientes para o aprimoramento da qualidade do ensino das escolas públicas alagoanas. Além disso, por outro lado, a pesquisa contribui para a sociedade de forma geral, tendo em vista que as variáveis discutidas, bem como as propostas esquematizadas, agregam conhecimento aplicável a todo o sistema educacional de Ensino Médio brasileiro.

A partir dessas assertivas, a discussão proposta neste artigo está estruturada em cinco seções. $\mathrm{Na}$ introdução, procede-se a uma abordagem da problemática, sendo apresentados o tema, a justificativa e os objetivos deste artigo. Em seguida, na seção 2, são apontadas as bases conceituais sobre o tema. Posteriormente, na seção 3, apresenta-se a descrição dos procedimentos metodológicos. Os resultados obtidos pelas evidências empíricas são apresentados na seção 4 . $\mathrm{Na}$ seção 5 são apresentadas as considerações finais do estudo. Por fim, as referências bibliográficas.

\section{REFERENCIAL TEÓRICO}

\section{O Exame Nacional do Ensino Médio brasileiro - Enem}

\section{Breve histórico do Enem}

A partir de meados da década de 90 do século XX, acentuaram-se os movimentos pela democratização do acesso à educação superior no Brasil. Isso resultou na criação do Fundo de Financiamento Estudantil (FIES), do sistema de cotas para alunos negros e de escolas públicas, da isenção da taxa de inscrição para o vestibular e do Exame Nacional de Ensino Médio (ENEM) (Dourado, Catani e Oliveira, 2016)

Em 2002, o Ensino Médio alcançou número de matrículas 53\% maior do que no período de 1996, com o total de 8.710 .584 matrículas. Não foi diferente em relação ao Ensino Superior, cujo número de vagas subiu de 1.540,080 para 3.030.754. Apesar do aumento do número de vagas nas Instituições de Ensino Superior, o acesso a esse nível do ensino era impregnado pela seletividade social e étnica. A proporção de alunos pertencentes à parcela dos $20 \%$ mais ricos do país passou de $67 \%$ para $70 \%$ no período, enquanto a presença dos $20 \%$ mais pobres diminuiu de 1,3\% para 0,9\% (Dourado; Catani; Oliveira, 2016).

O Exame Nacional do Ensino Médio (ENEM) foi criado em 1998, com a finalidade de avaliar o perfil de saída dos alunos em fase de conclusão do Ensino Médio em todo o país. A partir daí, gradualmente, outros usos foram incorporados, dentre eles o critério parcial ou exclusivo para o ingresso 
às universidades vinculadas ao processo de ingresso adotado pelo Ministério da Educação (MEC). Bolsas e créditos estudantis financiados pelo governo também entraram na lista de novos usos vinculados ao ENEM. A mais nova aplicação, porém, é a de ser uma certificação oficial de conclusão do Ensino Médio no país (ANDRADE; SOIDA, 2015).

Em sua primeira realização, em 1998, 157.221 pessoas prestaram o exame. Em 2016, são 8.647.000 inscrições, das quais 30\% correspondem a abstenções, tendo 768 candidatos sido eliminados por irregularidades. Foi, porém, a partir de 2004 que o MEC passou a divulgar as médias obtidas por cada aluno na prova do ENEM. Com isso, deu-se o início à criação do ranking das escolas do Ensino Médio baseado nos resultados do ENEM, em que a posição de uma escola é determinada exclusivamente pelo desempenho de seus alunos na prova.

\section{Notas técnicas explicativas dos indicadores e do exame em geral}

Segundo a atual nota técnica do MEC, os resultados obtidos pelo ENEM podem ser utilizados para compor a avaliação de medição da qualidade do Ensino Médio no país; a implementação de políticas públicas; a criação de referência nacional para o aperfeiçoamento dos currículos do Ensino Médio; e o desenvolvimento de estudos e indicadores sobre a educação brasileira. Além disso, o MEC utiliza o exame para aferir as competências e habilidades desenvolvidas pelos estudantes ao fim da escolaridade básica.

Esse sistema de avaliação foi implantado também no ensino superior brasileiro. No âmbito do ensino superior, foi adotado o Exame Nacional de Cursos (ENC). Tais instrumentos de julgamento - como o ENEM e o ENC - focados no produto e na informação ao cliente-consumidor de serviços e produtos acadêmicos promoveram uma competição por meio do ranqueamento das instituições de ensino, que contribuiu para a avaliação da qualidade do ensino, controle da oferta e definição de políticas públicas baseadas na expansão competitiva do ensino superior. A avaliação centralizada e o ranqueamento das instituições de ensino articularam um sistema educacional competitivo, voltado à eficiência, desempenho e produtividade (Dourado; Catani; Oliveira, 2016)

Os resultados do ENEM auxiliam estudantes, pais, professores, diretores das escolas e gestores educacionais nas reflexões sobre o aprendizado dos estudantes no Ensino Médio e no estabelecimento de estratégias em favor da melhoria da qualidade da educação. Quando disponibilizados por escola, os resultados agregados das proficiências, em termos de médias e percentuais de 
estudantes por nível da escala apresentados por Área do Conhecimento e Redação, possibilitam análises por parte da comunidade escolar quanto aos desafios a serem enfrentados.

Para análise dos resultados, além das notas por área de conhecimento, são utilizados também indicadores contextuais que permitem melhor compreensão da realidade de cada escola e uma análise mais adequada de seus resultados de proficiência, uma vez que esses estão associados às características e contexto das escolas e seus alunos.

Os indicadores apresentados são:

- Indicador de Nível Socioeconômico (Inse): o Inse possibilita, de modo geral, situar o público atendido pela escola em um estrato social, apontando o padrão de vida referente a cada um de seus níveis ou estratos. Esse indicador é calculado a partir do nível de escolaridade dos pais e da posse de bens e contratação de serviços pela família dos alunos.

- Indicador de Formação Docente: o Indicador de Adequação da Formação Docente analisa a formação dos docentes que lecionam no Ensino Médio na escola. Apresenta o percentual de disciplinas que são ministradas por professores com formação superior de Licenciatura (ou Bacharelado com complementação pedagógica) na mesma disciplina que leciona.

- Indicador de Permanência na Escola (Ensino Médio): O Indicador de Permanência na Escola apresenta o percentual de participantes que cursaram todo o Ensino Médio na mesma escola. Ou seja, apenas os alunos participantes, considerados nos resultados da escola, são contabilizados no percentual divulgado.

\section{Pontos favoráveis ao Enem}

Andriola (2011) relata que as questões do ENEM não se atêm apenas aos conteúdos escolares, como no vestibular, mas avaliam as habilidades e as competências a partir de problemas cuja solução não depende unicamente do domínio do conhecimento formal do aluno sobre os conteúdos escolares. Assim, não importa apenas o que o aluno sabe, mas também sua capacidade de processar informações.

Outro ponto destacado pelo autor é que a prova aborda peculiaridades regionais, naturais, culturais e históricas do Brasil, bem como seus problemas sociais, promovendo reflexões acerca das possíveis respostas ou saídas aos problemas nacionais.

Santos (2004) registra que impõe uma proposta pedagógica voltada ao aprendizado de conhecimentos relevantes para o cidadão enquanto ser social. Afasta-se o foco do sistema educacional da simples aquisição de conhecimento 
e domínio de conteúdos escolares. Contribui para o desenvolvimento de competências que possibilitam aos alunos o acesso às áreas tecnológicas, de pesquisa científica e ao mercado de trabalho.

Outro ponto que merece destaque é a mobilidade regional dos candidatos, que passam a concorrer às vagas das Instituições de Ensino Superior em âmbito nacional.

\section{Críticas ao modelo}

Um fato a ser observado nas análises feitas aos rankings dos três anos examinados neste artigo é que o tamanho de uma escola, medido pelo número de alunos que realizam o ENEM, afeta o desempenho da mesma no ranking. Escolas menores estão mais associadas a pontuações extremas (baixas ou altas). Além disso, as oscilações no desempenho de um ano para outro são mais significativas nas escolas de menor porte. $\mathrm{Na}$ comparação realizada entre escolas públicas e privadas, é verificado que as privadas apresentam uma distribuição menos homogênea, talvez por serem escolas na média de menor porte, e com rendimentos superiores (ANDRADE; SOIDA, 2015). Ainda assim, é preciso verificar as possíveis variações específicas de cada estado que, de certa forma, interferem no resultado final da colocação no ranking.

O desempenho médio das escolas não é suficiente para que seja alcançada uma comparação justa e de qualidade entre as escolas, mesmo quando se trata apenas de escolas somente públicas ou somente privadas. Todo resultado de avaliação do desempenho escolar resulta num conjunto de fatores interrelacionados, entre os quais destacam-se o histórico escolar familiar, atributos individuais e experiências vivenciadas pelos alunos, além da qualidade do ensino oferecido na escola atual (CURI, 2009). Portanto, a comparação entre escolas apenas pela nota do ENEM não é adequada, porque não leva em consideração diversos fatores determinantes da qualidade de ensino de cada instituição: por exemplo, a formação de professores, o tamanho da escola, a seleção de alunos e o padrão de vida das famílias dos estudantes.

Outra crítica que pode ser discutida se refere aos indicadores, haja vista que, ano após ano, estes vêm sendo alterados. Em 2013, tinha-se como indicadores o porte da escola, nível socioeconômico e formação docente; Em 2014, indicador de permanência e nível socioeconômico; Em 2015, porte da escola, nível socioeconômico, indicador de permanência e formação docente. 


\section{Políticas públicas voltadas à educação básica}

Políticas públicas é uma expressão que visa à compreensão de uma situação restrita da política; refere-se à participação da sociedade nas decisões da cidade, do território. Além disso, entende-se por políticas públicas tudo o que um governo faz e deixa de fazer, tendo suas ações e omissões impacto direto no povo (OLIVEIRA; PIZZIO; FRANÇA, 2010). No entanto, para melhor compreensão do que são as políticas públicas, são definidos alguns conceitos referentes aos conceitos interligados ao tema: policy; politics; polity; policy network; policy arena; e policy cicle. Define-se polity como uma dimensão institucional referente à ordem do sistema político, esboçada pelo sistema jurídico, e à estrutura institucional do sistema político-administrativo. O termo politics insere-se no quadro da dimensão processual política, geralmente de caráter conflituoso. Em relação à dimensão material, o temo policy refere-se aos conteúdos concretos, isto é, à configuração dos programas políticos, aos conflitos técnicos e a todo o conjunto material das decisões políticas. Emprega-se o termo policy network para as interações das distintas organizações e grupos do executivo, do legislativo e da sociedade na criação e implementação de uma policy. O modelo policy arena é oriundo de custos e ganhos que a sociedade espera das medidas adotadas pelo governo, fruto do processo político. Dessa forma, o policy arena refere-se aos processos de conflito e de consenso inseridos nas diversas áreas de política, as quais podem ser diferenciadas de acordo com seu perfil distributivo, redistributivo, regulatório ou constitutivo. Por fim, um elemento importante a ser tratado na abordagem da policy analysis é o chamado policy cicle (ciclo de políticas públicas), que é um esquema de visualização e interpretação que organiza a vida de uma política pública em fases sequenciais e interdependentes: 1 - identificação do problema; 2 - formação da agenda; 3 - formulação das alternativas; 4 - tomada de decisão; 5 - implementação; 6 - avaliação; e 7 - extinção (FREY, 2009).

As políticas públicas educacionais dizem respeito à educação escolar. No entanto, isso não significa que haja uma circunscrição da educação ao ambiente escolar. Segundo Oliveira, Pìzzio e França (2012), todo o aprendizado social referente a família, igreja, escola, trabalho, rua, teatro, etc é resultado da observação, da repetição, da reprodução, da inculcação, tudo isso vinculado a educação. No entanto, é o ambiente escolar local propício para a estruturação de um clima educacional, visto que funciona como uma comunidade em que há uma articulação entre diversos interessados: alunos, professores, servidores, pais, vizinhança e Estado, no sentido de sociedade política que articula o sistema 
por meio de políticas públicas, entendidas essas como processo relacionado às decisões do governo que têm incidência no ambiente escolar enquanto ambiente de ensino-aprendizagem.

A partir disso, tais decisões do Estado envolvem construção de prédios, concursos públicos para contratação de profissionais, capacitação, formação docente, valorização profissional, gestão escolar, dentre outras ações. No final de todas essas ações, compõem-se uma regulação e uma orientação para o sistema de ensino, instituindo-se a educação escolar.

Políticas públicas educacionais são um elemento de normatização do Estado que tem como principal fonte de implementação na educação a Lei de Diretrizes e Bases da Educação Nacional (LDB). Identificam-se em Alagoas índices educacionais que inserem o estado entre os piores do Brasil no ranking do ENEM. Talvez, por essa razão, acredita-se que as políticas educacionais em Alagoas precisam ser constantemente revisadas e continuamente melhoradas, com o objetivo de se buscarem resultados cada vez mais progressivos. As notas no ENEM são reflexo tanto de uma cultura educacional apontada em determinada região, como também dos investimentos empregados em políticas públicas educacionais. Ainda assim, trata-se de um ranking polêmico, que, na opinião de alguns estudiosos, não reflete com total detalhamento a realidade da qualidade de ensino das escolas, fazendo com que algumas variáveis específicas, muitas vezes regionalizadas, não sejam referenciadas.

A gestão da educação pública do estado de Alagoas, bem como em conjunto com o governo federal, através do MEC, tem buscado implementar ações específicas. O Pacto Nacional pelo Fortalecimento do Ensino Médio é um exemplo de articulação e coordenação de ações e estratégias entre a União e os governos estaduais e distrital na formulação e implantação de políticas para elevar o padrão de qualidade do Ensino Médio brasileiro, nas mais diversas modalidades, com o propósito de realizar a inclusão de todos. O governo de Alagoas tem firmado parceria com o MEC e efetuado a adesão a esse Pacto, com a finalidade de melhorar o patamar do estado no que se refere à qualidade do Ensino Médio alagoano. Outro projeto em execução, visando à capacitação dos alunos para a realização da prova do ENEM, é o Aulão Pré-ENEM Comunitário, realizado pela Universidade Federal de Alagoas (UFAL), através da Pró-reitoria de extensão (Proex), que disponibiliza aulas gratuitas para cerca de 300 estudantes oriundos de escolas públicas. Além disso, a Secretaria de Estado da Educação de Alagoas (SEDUC) também realiza o chamado Aulão para cerca de 4.000 alunos, sendo mais de 1.000 do interior do estado. Os professores participantes desse aulão são voluntários tanto da rede pública, como também da rede privada. 
Dentre as ações governamentais que visam à melhoria da qualidade do Ensino Médio do estado de Alagoas, está em execução o Núcleo Estratégico de Acompanhamento Pedagógico, em parceria com a Fundação Lemann. O objetivo é promover a articulação e a coordenação de ações estratégicas das ações continuadas a partir do acompanhamento pedagógico da rede estadual, para se alcançar a melhoria da qualidade de ensino das escolas da rede. De um total de 210 escolas públicas estaduais, o governo alagoano, em parceria com o MEC, passa de 16 escolas em tempo integral em 2016 para 34 em 2017, por meio do Programa de Ensino Integral, ação que se iniciou em 2015. A essência desse programa é a permanência do estudante na escola, assistindo-o integralmente em suas necessidades básicas e educacionais. Dessa forma, resulta melhor aproveitamento escolar e capacidade para atingir efetivamente a aprendizagem.

Outra ação da gestão estadual de ensino foi a construção coletiva de um documento denominado Referencial Curricular da Educação Básica da Rede Estadual de Ensino de Alagoas. A atual versão do documento, vigente desde 2014, foi desenvolvida com a participação de professores da rede estadual de ensino, técnicos pedagógicos da Secretaria de Estado de Educação de Alagoas, bem como consultores especialistas em cada área de conhecimento. O objetivo do Referencial é traçar orientações para a organização da sua prática pedagógica. Diante disso, uma gerência foi criada com a finalidade de planejar o processo de construção do Referencial em três grandes etapas, que se iniciaram em 2011, tendo sequência em 2012 e finalizando-se em 2013, sendo implementado a partir de 2014.

\section{METODOLOGIA}

Formulou-se um estudo com a intenção de se identificarem fatores decisivos para a diferença na qualidade do Ensino Médio das escolas brasileiras a partir do ranking de desempenho no Exame Nacional do Ensino Médio (ENEM) elaborado pelo Instituto Nacional de Estudos e Pesquisas Educacionais Anísio Teixeira (INEP) e, a partir disso, proporem-se ações para aprimorar o Ensino Médio das instituições educacionais brasileiras.

A pesquisa baseou-se na análise documental das informações coletadas do sítio eletrônico do INEP, a partir da qual que esquematizou um ranking de desempenho das escolas brasileiras no ENEM. Empregou-se o método de coleta descritivo, com reunião de dados por meio de levantamento bibliográfico, análise documental e entrevistas. Registraram-se as principais características das escolas 
com melhor desempenho no ENEM da região nordeste do país a fim de esclarecer os principais fatores que contribuíram para seu bom desempenho. Em seguida, estabeleceram-se relações entre variáveis.

Realizou-se a pesquisa documental por meio da investigação dos temas "Avaliação do Exame Nacional do Ensino Médio (ENEM)" e "Qualidade das Instituições de Ensino Médio do Brasil" nos sistemas de busca do Google Acadêmico e do sistema de pesquisa Spell. Os termos usados na busca foram: Exame Nacional do Ensino Médio, ENEM, INEP, qualidade do Ensino Médio brasileiro, avaliação do Ensino Médio do Brasil e comparação entre escolas brasileiras. Pesquisaram-se, ainda, as mesmas expressões no idioma inglês.

Usou-se a abordagem de pesquisa quali-quantitativa, também definida como método misto (Creswell, 2007). Por um lado, examinaram-se dados estatísticos e precisos, atinentes ao desempenho das escolas mensurado pelo INEP e, por outro, critérios não quantificáveis associados ao método de ensino de escolas selecionadas.

Quanto à amostra, examinou-se o ranking das escolas cujos estudantes participaram do ENEM nos anos de 2013 a 2015. Para isso, investigaram-se todos os estudos realizados sobre o tema, identificando-se o do INEP como mais confiável. Em seguida, comparou-se a classificação das escolas da Região Nordeste para localizar as melhores classificadas e os fatores que podem ter influenciado seu desempenho. Aplicou-se o procedimento de survey, com uso de protocolo de observação para se identificarem as variáveis que representaram maior influência no ranking.

Na etapa seguinte, contrastaram-se os fatores arrolados com outros estudos voltados à avaliação do Ensino Médio nacional e internacional, a fim de reafirmar a pertinência das conclusões obtidas. Para isso, replicou-se o procedimento de busca em periódicos nacionais voltados ao campo de interesse da administração, tais como RAE-Eletrônica, RAC, RAP e Rausp.

\section{ANÁLISE DOS DADOS}

Como já relatado anteriormente, não houve entre os anos de 2013 a 2015 a manutenção dos mesmos indicadores nas tabelas de resultados do ENEM disponibilizadas pelo INEP. Dessa forma, restou inviável a verificação da evolução ano a ano de todos os indicadores, sendo possível apenas a análise do indicador de nível socioeconômico. A busca de maior confiabilidade e transparência do ranking do ENEM, faz o MEC efetuar mudanças constantes através de novos indicadores. Na tabela abaixo, verifica-se a composição dos indicadores por ano. 
Tabela 1 - Indicadores presentes de 2013 a 2015

\begin{tabular}{|c|c|c|c|c|}
\hline & $\begin{array}{c}\text { Nível } \\
\text { socioeconômico }\end{array}$ & $\begin{array}{c}\text { Indicador de } \\
\text { Permanência }\end{array}$ & $\begin{array}{c}\text { Indicador de } \\
\text { formação docente }\end{array}$ & Porte da escola \\
\hline 2013 & SIM & NÃO & SIM & SIM \\
\hline 2014 & SIM & SIM & NÃO & NÃO \\
\hline 2015 & SIM & SIM & SIM & SIM \\
\hline
\end{tabular}

Fonte: Elaborado pelos autores

Com relação às médias das escolas públicas estaduais no nordeste, observa-se que todos os estados elevaram suas médias entre os anos de 2013 e 2014, e entre os anos de 2014 e 2015, mantiveram sua média, com pequenas variações. A exceção fica por conta de Alagoas, que teve drástica queda em seu desempenho.

Gráfico 1 - Média das notas das escolas ano a ano

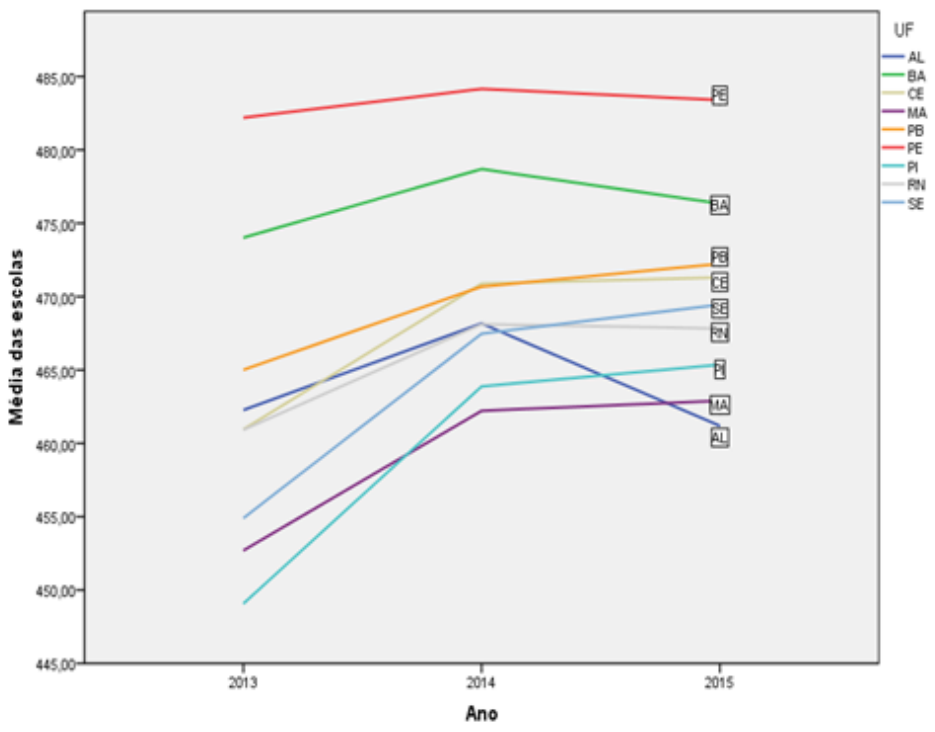

Fonte: Elaboração dos autores

Como forma de melhor analisar a queda de desempenho de Alagoas nos anos de 2014 e 2015, comparou-se a execução orçamentária das secretarias de educação dos estados de Alagoas e Sergipe - estados vizinhos geograficamente e com dimensões físicas e populacionais semelhantes. Assim, verificou-se, conforme a tabela 2 , redução de aproximadamente $11 \%$ no valor gasto com educação em Alagoas. De acordo com a tabela 3, em Sergipe, o montante gasto 
se manteve praticamente inalterado em relação ao ano anterior, com uma redução de aproximadamente 3\%. Identifica-se que o montante da receita de recursos destinados à educação em Sergipe é maior que em Alagoas, conforme a Tabela 2, ou seja, a condição econômica do estado sergipano é favorável a um maior poder de investimento na educação. Porém, não basta apenas obter receita, é imprescindível que os recursos sejam utilizados de fato nas ações governamentais oriundas do planejamento orçamentário. Nos anos de 2013, 2014 e 2015, o estado de Sergipe obteve respectivamente 81,69\%, 93,87\% e 91,50\% de recursos executados na área da educação, o que mantém uma coerência com a evolução da qualidade da educação local e compatibilidade com a melhora da média das notas no ranking do ENEM, conforme o Gráfico 1. Em Alagoas, além de obter, de acordo com a Tabela 2, receita menor que o estado de Sergipe, obteve sequencialmente uma queda na execução dos recursos destinados à educação nos anos de 2013, 2014 e 2015, com os percentuais de 95,93\%, 88,16\% e 79,61\%, respectivamente. Essa involução na execução dos recursos orçamentários refletese negativamente na posição do estado de Alagoas nos indicadores educacionais e na média das notas do ENEM, de acordo com o Gráfico 1. Não basta apenas captar recursos e elaborar políticas públicas educacionais revolucionárias; deve haver uma fiscalização constante da execução dos recursos em prol dos objetivos das ações governamentais e consequentemente da qualidade do ensino público.

Dessa forma, supõe-se que a manutenção das médias das escolas sergipanas e a queda das médias das escolas alagoanas sofreram influência também do orçamento aplicado na educação nesses dois estados.

\section{Tabela 2 - Execução Orçamentária em Alagoas}

\begin{tabular}{|c|c|c|c|c|}
\hline Ano & Função & Unidade gestora & Dotação inicial & $\begin{array}{c}\text { Total } \\
\text { desembolsado }\end{array}$ \\
\hline 2013 & Educação & $\begin{array}{c}\text { Secretaria Estadual } \\
\text { da Educação }\end{array}$ & $\mathrm{R} \$ 784.569 .131,00$ & $\mathrm{R} \$ 747.887 .851,10$ \\
\hline 2014 & Educação & $\begin{array}{c}\text { Secretaria Estadual } \\
\text { da Educação }\end{array}$ & $\mathrm{R} \$ 851.370 .266,00$ & $\mathrm{R} \$ 750.645 .024,03$ \\
\hline 2015 & Educação & $\begin{array}{c}\text { Secretaria Estadual } \\
\text { da Educação }\end{array}$ & $\mathrm{R} \$ 836.529 .409,00$ & $\mathrm{R} \$ 665.996 .987,87$ \\
\hline
\end{tabular}

Fonte: http://transparencia.al.gov.br/ 
Tabela 3 - Execução Orçamentária em Sergipe

\begin{tabular}{|c|c|c|c|c|}
\hline Ano & Função & Unidade gestora & Dotação inicial & $\begin{array}{c}\text { Total } \\
\text { desembolsado }\end{array}$ \\
\hline 2013 & Educação & $\begin{array}{c}\text { Secretaria Estadual } \\
\text { da Educação }\end{array}$ & $\begin{array}{c}\mathrm{R} \$ \\
1.144 .894 .750,00\end{array}$ & $\mathrm{R} \$ 935.330 .353,04$ \\
\hline 2014 & Educação & $\begin{array}{c}\text { Secretaria Estadual } \\
\text { da Educação }\end{array}$ & $\begin{array}{c}\mathrm{R} \$ \\
1.081 .576 .143,00\end{array}$ & $\begin{array}{c}\mathrm{R} \$ \\
1.015 .295 .355,37\end{array}$ \\
\hline 2015 & Educação & $\begin{array}{c}\text { Secretaria Estadual } \\
\text { da Educação }\end{array}$ & $\begin{array}{c}\mathrm{R} \$ \\
1.072 .802 .300,00\end{array}$ & $\mathrm{R} \$ 981.713 .422,99$ \\
\hline
\end{tabular}

Fonte: http://www.transparenciasergipe.se.gov.br/

Analisando-se o único indicador presente nos três anos deste estudo, o nível socioeconômico, observa-se que o verificado no gráfico 1 (queda no desempenho geral de Alagoas) parece ter sido afetado pelo demonstrado no gráfico 2, ou seja, verifica-se que Alagoas foi o estado a ter a maior queda do nível econômico social dentre os estados do nordeste.

\section{Gráfico 2 - Evolução do nível socioeconômico}

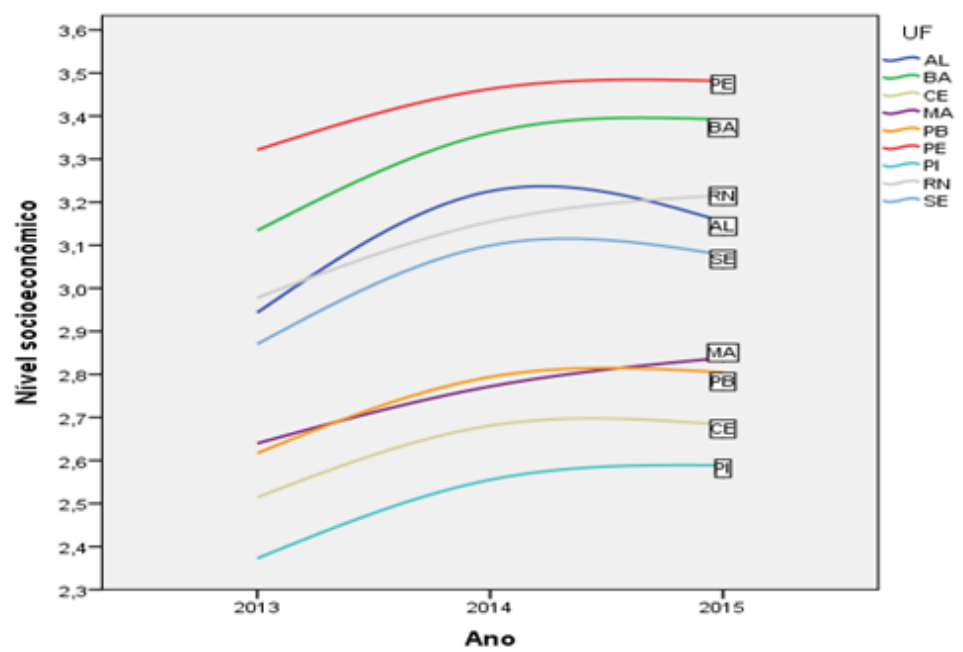

Fonte: Elaboração dos autores

Ultrapassando a evolução das notas de 2013 a 2015, analisaram-se especificamente os resultados das escolas públicas estaduais no ano de 2015. Observa-se no gráfico 3 que Alagoas detém o pior desempenho, enquanto os melhores desempenhos encontram-se nos estados de Pernambuco e Bahia, respectivamente. 
Dessa forma, intencionando-se propor políticas públicas para elevação do desempenho de Alagoas, optou-se por comparar as escolas alagoanas com as melhores do nordeste. Para tanto, selecionaram-se as cinquenta melhores escolas públicas estaduais de Pernambuco e as cinquenta melhores escolas públicas estaduais da Bahia e relacionaram-se seus índices e suas notas com os índices e notas da totalidade de escolas de Alagoas.

Quanto às notas, observa-se que as maiores diferenças entre as escolas alagoanas e as melhores do nordeste encontram-se nas disciplinas de redação e matemática, o que sugere que seja dada maior atenção a estas áreas nas escolas públicas estaduais de alagoas. Propõe-se que seja feito um mapeamento das escolas que têm carência de professores nessas áreas e seja realizada monitoria nas disciplinas escassas e um planejamento pedagógico capaz de suprir essa dificuldade.

Gráfico 3 - Escolas públicas estaduais 2015 - Nordeste

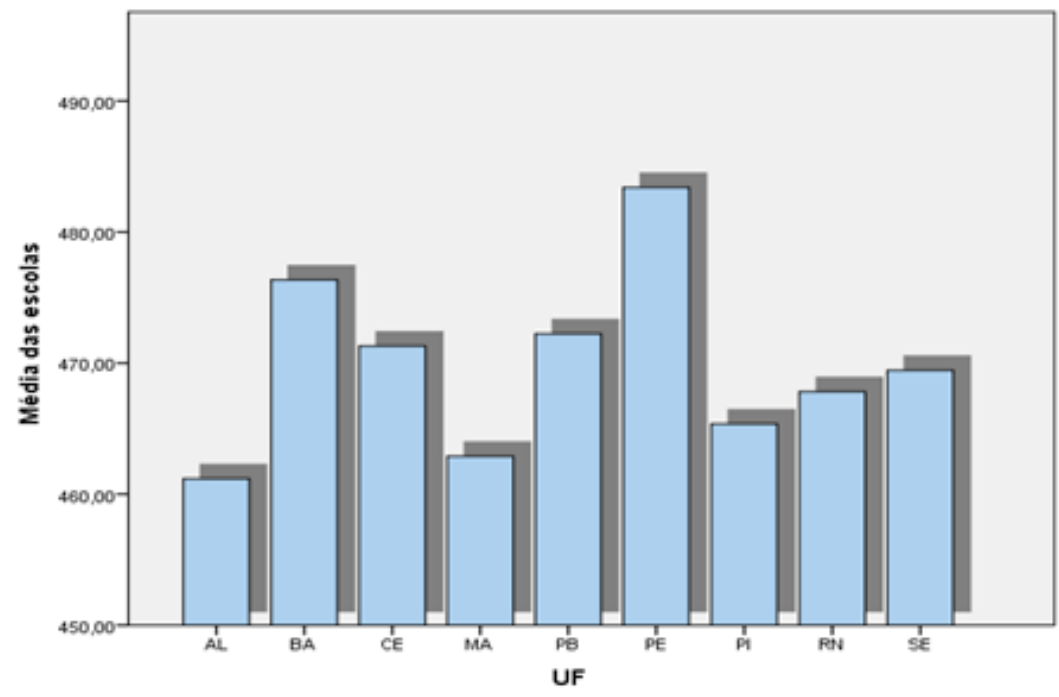


Tabela 4 - Notas 2015

\begin{tabular}{|c|c|c|c|c|c|c|c|}
\hline \multicolumn{2}{|c|}{} & $\begin{array}{c}\text { Média } \\
\text { Geral }\end{array}$ & Linguagens & Matemática & $\begin{array}{c}\text { Ciências } \\
\text { Humanas }\end{array}$ & $\begin{array}{c}\text { Ciências } \\
\text { da } \\
\text { Natureza }\end{array}$ & Redação \\
\hline $\begin{array}{c}50 \text { melhores } \\
\text { Bahia }\end{array}$ & Média & 504,95 & 507,53 & 471,07 & 563,86 & 477,33 & 563,53 \\
\cline { 2 - 8 } & $\mathrm{N}$ & 50 & 50 & 50 & 50 & 50 & 50 \\
\hline $\begin{array}{c}50 \text { melhores } \\
\text { Pernambuco }\end{array}$ & Média & 518,49 & 516,89 & 496,42 & 570,86 & 489,77 & 586,99 \\
\cline { 2 - 8 } & $\mathrm{N}$ & 50 & 50 & 50 & 50 & 50 & 50 \\
\hline $\begin{array}{c}\text { Geral } \\
\text { Alagoas }\end{array}$ & Média & 461,18 & 461,90 & 421,31 & 519,69 & 441,84 & 504,37 \\
\cline { 2 - 8 } & $\mathrm{N}$ & 84 & 84 & 84 & 84 & 84 & 84 \\
\hline
\end{tabular}

Quanto aos indicadores, conforme tabela 5, observa-se que apesar de Alagoas deter profissionais com mais elevada formação, esta variável parece não influir significativamente no desempenho das escolas. É possível que profissionais altamente capacitados numa determinada formação, estejam lecionando em outras áreas de formação nas escolas, o que pode gerar esse viés na correlação entre formação do professor e desempenho nas escolas.

Mais uma vez identificou-se a influência do nível socioeconômico no desempenho das escolas; observa-se que Alagoas possui indicador próximo ao nível baixo, enquanto os estados da Bahia e Pernambuco se aproximam do nível médio.

Não foram identificadas tendências positivas ou negativas no tocante aos indicadores de porte da escola e permanência do aluno. A idéia do INEP de criar o indicador de permanência nas escolas é facilitar as manobras das escolas para melhorar as notas, como as transferências de bons alunos do $3^{\circ}$ ano do Ensino Médio. 
Tabela 5 - Indicadores 2015

\begin{tabular}{|c|c|c|c|c|c|}
\hline \multicolumn{2}{|c|}{} & Porte da escola & $\begin{array}{c}\text { Indicador de } \\
\text { permanência }\end{array}$ & $\begin{array}{c}\text { Nível } \\
\text { socioeconômico }\end{array}$ & $\begin{array}{c}\text { Formação } \\
\text { docente (\%) }\end{array}$ \\
\hline \multirow{2}{*}{50 melhores Bahia } & Média & 3,30 & 4,34 & 3,98 & 43,08 \\
\cline { 2 - 6 } & $\mathrm{N}$ & 50 & 50 & 50 & 50 \\
\hline \multirow{2}{*}{50 melhores Pernambuco } & Média & 3,64 & 4,92 & 3,90 & 55,91 \\
\cline { 2 - 6 } & $\mathrm{N}$ & 50 & 50 & 50 & 50 \\
\hline \multirow{2}{*}{ Geral Alagoas } & Média & 3,08 & 4,38 & 3,15 & 56,01 \\
\cline { 2 - 6 } & $\mathrm{N}$ & 84 & 84 & 84 & 84 \\
\hline
\end{tabular}

- Porte da escola: 1 = de 1 a 30 alunos; 2 = de 31 a 60 alunos; 3 = de 61 a 90 alunos; 4 = maior que 90 alunos.

- Indicador de permanência: $1=$ Menos de 20\%; $2=$ de 20 a 40\%; $3=$ de 40 a $60 \% ; 4=$ de 60 a $80 \% ; 5=$ de 80 a $100 \%$.

- Nível socioeconômico: 1 = Muito baixo; 2 = baixo; 3 = médio baixo; 4 = médio; 5 = médio alto; $6=$ alto; 7 = muito alto.

Por fim, relacionou-se exclusivamente a variável de nível socioeconômico com a média das escolas públicas estaduais do nordeste. Mais uma vez, ratifica-se se que o nível socioeconômico interfere sobremaneira no desempenho das escolas, ou seja, quanto maior o nível socioeconômico, maior a tendência de se obterem notas mais elevadas. De forma geral, as escolas privadas e de menor porte são as mais bem classificadas no ENEM; já as melhores escolas públicas classificadas são, de uma forma geral, as que possuem um regime e orçamento diferenciados, em que estão incluídas práticas de seleção de alunos, como é o caso de algumas escolas militares. Dessa forma, para que o aluno participe com eficiência dessas seleções, exige-se um mínimo de condição estrutural, principalmente financeira, para que se consiga obter uma condição mínima de concorrer com os demais alunos. Dessa maneira, ratifica-se a influência socioeconômica. 


\section{Gráfico 4 - Nível socioeconômico x Média geral das escolas}

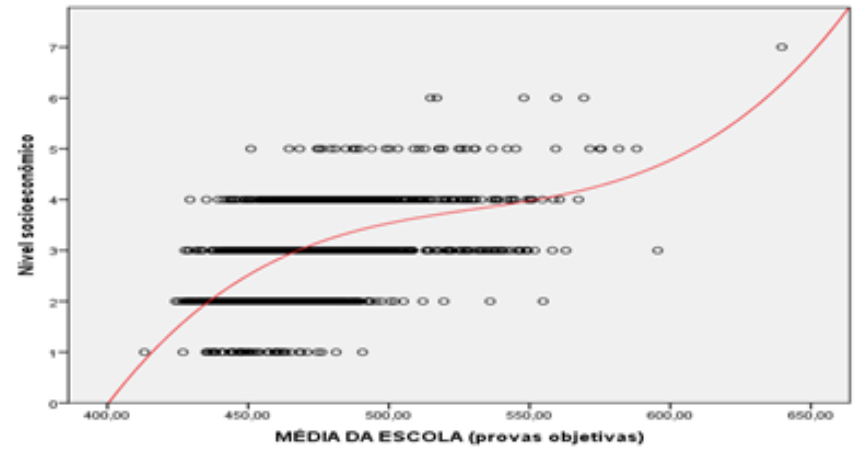

- Nível socioeconômico: 1 = Muito baixo; 2 = baixo; 3 = médio baixo; 4 = médio; 5 = médio alto; $6=$ alto; 7 = muito alto.

Com base nas observações feitas anteriormente, resta propor políticas públicas para que se eleve o nível educacional básico no Nordeste, mais especificamente em Alagoas. Políticas públicas em outras áreas específicas podem auxiliar, de certa forma, no contexto das políticas públicas educacionais, visto que estas não têm a capacidade imediata de interferir na condição socioeconômica da sociedade local. Dessa forma, sugere-se que a agenda governamental proponha uma ação conjunta entre os órgãos capazes de propor ações vinculadas às ações socioeconômicas, ou seja, as políticas públicas educacionais precisam estar conjugadas com as demais políticas públicas, para que seja criado um ciclo de desenvolvimento em diversos fatores sociais e econômicos.

\section{CONSIDERAÇÕES FINAIS}

Analisou-se no artigo que as políticas públicas educacionais adotadas precisam de remodelação e de melhor articulação com as demais políticas públicas implementadas pelo governo, para que o nível educacional mantenha uma melhoria contínua, assim como as demais áreas sociais. Uma das ações de remodelação que poderia ser adotada é o redimensionamento dos professores, de acordo com sua formação, ou seja, é preciso analisar se de fato os professores com determinada capacitação estão, de fato, lecionando em sua área específica, visto que isto pode causar um viés no ranking. Investimentos no social como um todo, principalmente na sociedade mais carente, bem como na economia local, também fazem parte desse ciclo da política pública educacional, visto que a condição socioeconômica influencia fortemente a posição no ranking das escolas. As melhores escolas públicas têm um nível socioeconômico mais elevado. 
Além disso, o ranking do ENEM deve ser encarado como uma lista, visto que o desempenho das escolas deve ser avaliado dentro dos contextos que permitam comparar similaridades e distinções entre as escolas, assim como entre os estados da federação e o distrito federal. Apontou-se que o ranking é inapropriado para indicar aos pais a qualidade da escola.

A reforma no Ensino Médio deve implicar novas modificações do ranking do ENEM, visto que diversas problemáticas estão em discussão entre o MEC e o Congresso Nacional. É válido lembrar que possíveis vieses podem ser abrandados com a adoção de medidas como a exclusão de alunos que utilizam a prova do ENEM apenas como treino, bem como a possibilidade de o exame não servir mais para certificar a conclusão do Ensino Médio. Além disso, a Medida Provisória (MP) 746/2016, propõe medidas que irão causar impactos nos próximos exames do ENEM. Dessa forma, propõe-se que novos estudos sejam realizados, a fim de se obter uma nova avaliação do ranking e sua proximidade com a realidade vivenciada em cada contexto, seja dos alunos, das escolas especificamente falando, ou de cada estado da federação.

\section{REFERÊNCIAS}

AGÊNCIA ALAGOAS. Notícias. Disponível em <http://agenciaalagoas. al.gov.br/noticia/item/9884-secretaria-promove-aulao-preparatorio-para-maisde-4-mil-estudantes> Acesso em 4 de jan. 2017.

ANDRADE, Eduardo; SOIDA, Ivan. A qualidade do ranking das escolas de Ensino Médio baseado no ENEM é questionável. Estudos Econômicos, v. 45, n. 2, p. 253-286, São Paulo, 2015.

ANDRIOLA, Wagner Bandeira. Doze motivos favoráveis à adoção do Exame Nacional do Ensino Médio (ENEM) pelas Instituições Federais de Ensino Superior (IFES). Ensaio: Aval. Pol. Públ. Educ., v. 19, n. 70, p. 107-25, 2011.

BARBOSA FILHO, F. H.; PESSOA, S. A. Educação e Crescimento: o que a evidência empírica e teórica mostra? Revista Brasileira de Economia, v. 11, p. 265-303, 2010.

CRESWELL, J. W. Projeto de pesquisa: métodos qualitativo, quantitativo e misto. Porto Alegre: Artmed, 2007. 
CURI, Andréa Zaitune et al. A relação entre mensalidade escolar e proficiência no enem. XXXVII Encontro Nacional de Economia [Proceedings of the 37th Brazilian Economics Meeting]. Anais... 2009.

DOURADO, Luiz Fernandes; CATANI, Afrânio Mendes; OLIVEIRA, João Ferreira. Políticas públicas e reformas da educação superior no Brasil: impasses e perspectivas. Pro-Posições, v. 15, n. 3, p. 91-115, 2016.

FREY, Klaus. Políticas públicas: um debate conceitual e reflexões referentes à prática da análise de políticas públicas no Brasil. Planejamento e políticas públicas, Rio de Janeiro, Instituto de Pesquisa Econômica Aplicada (IPEA), n. 21, p. 211-259, jun 2000.

INEP. Exame Nacional do Ensino Médio 2015. Brasília: Instituto Nacional de Estudos e Pesquisas educacionais Anísio Teixeira, 2016. Disponível em: < http:// portal.inep.gov.br/web/enem/enem>. Acesso em: 3 jan. 2017.

KAVESKI, Itzhak David Simão; MARTINS, José Augusto Sousa ; SCARPIN, Jorge Eduardo. A eficiência dos gastos públicos com o ensino médio regular nas instituições estaduais brasileiras. Enfoque: Reflexão Contábil, v. 34, p. 29-43, 2015.

MENEZES FILHO, Naércio A. Os determinantes do desempenho escolar do Brasil. São Paulo: IBMEC. Sumário Executivo, 2007. Disponível em: < https:/ / www.todospelaeducacao.org.br/arquivos/biblioteca/f4e8070a-8390-479c-a532803bbf14993a.pdf>. Acesso em: 5 de jan. 2017.

MINISTÉriO DA EDUCAÇÃO. Pacto do Ensino Médio. Disponível em: <http://pactoensinomedio.mec.gov.br/>. Acesso em: 4 de jan. 2017.

OLIVEIRA, Adão F. de; PIZZIO, Alex; FRANÇA, George. Políticas públicas educacionais: conceito e contextualização numa perspectiva didática. In: Oliveira, A. F.. (Org.). Fronteiras da Educação: desigualdades, ontologia e políticas educacionais. 01ed.Goiânia: Editora da PUC Goiás, 2010, v. 01, p. 95-104.

SANTOS, Boaventura de Sousa. A universidade no século XXI: para uma reforma democrática e emancipatória da universidade. Cortez, 2004. 
SECRETARIA DE ESTADO DA EDUCAÇÃO. Comunicação. Disponível em <http://www.educacao.al.gov.br/comunicacao/sala-de-imprensa/ noticias/2016/dezembro/em-2017-alagoas-tera-34-escolas-de-ensino-medioem-tempo-integral> Acesso em 4 de jan. 2017.

SECRETARIA DE ESTADO DA EDUCAÇÃO. Comunicação. Disponível em <http://www.educacao.al.gov.br/comunicacao/sala-de-imprensa/ noticias/2016/dezembro/seduc-publica-edital-para-acompanhamentopedagogico $>$ Acesso em 4 de jan. 2017.

PORTAL DA TRANSPARÊNCIA DE ALAGOAS. Transparência. Disponível em <http://transparencia.al.gov.br/> Acesso em 25 de jan. 2017.

PORTAL DA TRANSPARÊNCIA DE SERGIPE. Transparência Sergipe. Disponível em <http://www.transparenciasergipe.se.gov.br/> Acesso em 25 de jan. 2017.

UNIVERSIDADE FEDERAL DE ALAGOAS. Aulão Pré ENEM

Comunitário. Disponível em: <http://www.ufal.edu.br/utilidades/eventos/ aulao-pre-enem-comunitario $>$. Acesso em 4 de jan. 2017..

DANIEL CABRAL DE ALMEIDA é graduado em Administração pela Faculdade Estácio de Alagoas (2008). MBA em finanças Corporativas pela Universidade Gama Filho - RJ (2010). Atualmente é administrador do Instituto Federal de Alagoas lotado na Pro reitoria de administração. Mestrando em administração pública em rede nacional PROFIAP/UFAL. E-mail: danielcabral_@hotmail. com

VICTOR HUGO LESSA PIERRE é graduado em Direito pela Universidade Federal de Alagoas(2011) e especialista em Ciências Criminais pela Faculdade de Maceío (2015). Atualmente é Analista de Gestão Pública do Ministério Público do Estado de Alagoas. Mestrando em administração pública em rede nacional PROFIAP/ UFAL. E-mail: victorplhp@gmail.com

CARLOS EUGÊNIO SILVA DA COSTA é graduado em Administração de Empresas pela Universidade Federal de Alagoas (2007); Pós-graduado em Administração Pública pelo Instituto Prominas (2014); Administrador em uma unidade da Universidade Federal de Alagoas - UFAL, no Campus do Sertão, na cidade de Delmiro Gouveia/AL. Mestrando em administração pública em rede nacional PROFIAP/UFAL. E-mail: ceadm2011@gmail.com 
LUCIANA PEIXOTO SANTA RITA possui graduação em Economia pela Universidade Federal de Alagoas (1993), graduação em Direito pelo Centro de Estudos Superiores de Maceió (1994), mestrado em Administração pela Universidade Federal de Alagoas (1999) e doutorado em Administração pela Universidade de São Paulo (2004). Atualmente é Professora Associada II da Universidade Federal de Alagoas e ministra aulas no Curso de Graduação em Administração e nos Mestrados em Administração Pública (PROFIAP) e Economia Aplicada. Atua como pesquisadora nas seguintes áreas: cenários e políticas públicas, competitividade industrial, perfil tecnológico, economia de empresas e sistemas de inovação. Atua como pesquisadora na FIEA. Avaliadora do INEP e da EAD/CAPES. E-mail: lupsantarita@gmail.com

IBSEN MATEUS BITTENCOURT SANTANA PINTO é doutor em Administração de Empresas, Mestre Educação Brasileira na linha de Tecnologia da Informação e Comunicação - TIC, Especialista em Gestão de Turismo e Especialista em Matemática, Bacharel em Administração de Empresas e Bacharel em Turismo. Atualmente é Professor Adjunto I da Universidade Federal de Alagoas UFAL e Sócio-Proprietário da IT4LIFE que desenvolve software baseado em recomendações humanas empresa incubada no Núcleo de Inovação Tecnológica - NIT/PROPEP/UFAL. E-mail: ibsen.ead@gmail.com

Recebido em janeiro de 2017 Aprovado em março de 2017 